\title{
Analysis of maturity level of the management system in hotel sector companies
}

Autores

Alexander Parody Muñoz, Malory Beatriz Guerra Lara, Wilfrido Montes Lopesierra, Bulmaro Fuentes Morales, Miguel Santana

\section{Abstract}

The main purpose of this research is to evaluate the impact of maturity in quality management systems on assets, income and current ratio in companies of the hotel sector in the city of Barranquilla and its metropolitan area, based on the analysis of the level of maturity of the system and the application of multivariate statistical models. To achieve this, the Business Management strategies of this sector were characterized, based on a structured model of variables and based on field data referring to a representative sample of companies in the sector $(n=64)$. With this information, the determining factors in the level of maturity of the quality management systems were identified, which allowed to know if the processes developed in a management system, such as these, in the Hotel Sector, impact positively or negatively on the performance of the sector's companies based on assets, income and the current ratio by means of a multiple regression model, since, although these processes are being implemented, there are no current studies that evidence the contributions to the performance of the sector's companies.

Palabras clave:

Level of implementation, Organizational system, Formal and informal management system, Quality system, Business economic performance 